\title{
ROS-mediated activation of AMPK plays a critical role in sulforaphane-induced apoptosis and mitotic arrest in AGS human gastric cancer cells
}

\author{
Yung Hyun $\mathrm{Choi}^{1,2}$ \\ ${ }^{1}$ Department of Biochemistry, Dongeui University College of Korean Medicine, 52-57, Yangjeong-ro, Busanjin, Busan 614-052, \\ Republic of Korea \\ ${ }^{2}$ Anti-Aging Research Center and Blue-Bio Industry RIC, Dongeui University, 176 Eomgwangno Busanjin-gu, Busan 614-714, \\ Republic of Korea
}

\begin{abstract}
In this study, we investigated the role of AMP-activated protein kinase (AMPK) and the importance of reactive oxygen species (ROS) in apoptosis induction associated with cell cycle arrest induced by sulforaphane in AGS human gastric cancer cells. Our results demonstrated that sulforaphane inhibited proliferation of AGS cells by promoting apoptosis and accumulating the cellular portion of the G2/M phase via the buildup of cyclin B1 and cyclin-dependent kinase p21 (WAF1/CIP1). Moreover, the phosphorylation of histone H3 was markedly increased following treatment with sulforaphane, indicating that sulforaphane stimulated mitotic arrest. Sulforaphane concurrently induced phosphorylation of AMPK; however, compound C, an AMPK inhibitor, significantly blocked sulforaphane-induced apoptosis, suggesting that sulforaphane induces apoptosis of AGS cells through the AMPK-dependent pathway. Sulforaphane also activated the mitochondrial apoptotic signaling pathway with a decrease in mitochondrial membrane potential and the nuclear translocation of cytochrome $c$. Furthermore, sulforaphane provoked the generation of intracellular ROS; especially when ROS production was blocked by antioxidant $\mathrm{N}$-acetylcysteine, both AMPK activation and growth inhibition by sulforaphane were completely abolished. Collectively, these findings suggest that sulforaphane inhibited growth of AGS cells, which was mediated by a complex interplay between cellular mechanisms governing redox homeostasis, apoptosis, and cell cycle arrest through an ROS/AMPK-dependent pathway.
\end{abstract}

Key words: Sulforaphane - Cell cycle arrest - Apoptosis - ROS - AMPK

\section{Introduction}

Cell cycle deregulation, which leads to uncontrolled cell proliferation, is one of the most frequent changes occurring during tumor development. Thus, inducing arrest of cell cycle progression is an effective way to regulate abnormal proliferation of cancer cells. Induction of apoptosis, a programmed cell death, with cell cycle control has also been evaluated as a major mechanism for the removal of cancer cells (Diaz-Moralli et al. 2013; Koff et al. 2015). Therefore, de-

Correspondence to: Yung Hyun Choi, Department of Biochemistry, Dongeui University College of Korean Medicine, 52-57, Yangjeongro, Busanjin, Busan 47227, Republic of Korea

E-mail: choiyh@deu.ac.kr veloping appropriate methods to overcome these behaviors of cancer cells without affecting normal cells is recognized as the most basic process of cancer treatment (Visconti et al. 2016; Westhoff et al. 2016). Furthermore, cancer cells often exhibit several types of mitochondrial dysfunction, including mitochondrial DNA mutations, changes in energy metabolism, increased reactive oxygen species (ROS) production, and increased mitochondrial membrane potential (MMP), which may be key targets for cancer cell proliferation blocking. Especially, the loss of MMP damages mitochondrial function and induces ROS production; therefore, natural products that are likely to affect intracellular energy and metabolism have recently become the subject of investigation as promising anticancer agents (Rehman et al. 2014; Redza-Dutordoir and Averill-Bates 2016). 
Many recent epidemiological data have shown that intake of cruciferous vegetables that are rich in dietary isothiocyanates is positively correlated with the incidence of diverse tumors (Tang et al. 2010; Liu et al. 2013). Sulforaphane is a natural isothiocyanate derived from cruciferous vegetables like broccoli and Brussels sprouts (Myzak and Dashwood 2006; Fimognari et al. 2008). This phytochemical has a strong antioxidant potential and has proven to be an important cancer-preventive candidate, exhibiting high activity that inhibits the proliferation of cancer cells and induces apoptosis in many cancers (Gupta et al. 2014; Sestili and Fimognari 2015). Although inhibition of the proliferation of cancer cells by sulforaphane in some cell lines has been reported to be associated with G1 arrest in the cell cycle (Shen et al. 2006; Bryant et al. 2010; Wang et al. 2012), many studies have shown that it induces $\mathrm{G} 2 / \mathrm{M}$ arrest associated with apoptosis in multiple cancer types (Singh et al. 2004; Matsui et al. 2007; Chu et al. 2009; Suppipat et al. 2012; Wang et al. 2015; Byun et al. 2016; Shang et al. 2017). The effects of sulforaphane on cell cycle progression have also been reported to be specific for mitotic arrest, but not the G2 phase, which is associated with destruction of microtubule polymerization (Jackson and Singletary 2004; Mi et al. 2008; Xiao et al. 2012). In addition, it has been shown in various previous studies that ROS act as key regulators in the induction of apoptosis by sulforaphane (Singh et al. 2004; Wang et al. 2015; Byun et al. 2016; Shang et al. 2017). Further, recent results from Mondal et al. (2016) demonstrate that induction of apoptosis and inhibition of migration of human gastric cancer cells by sulforaphane are associated with increased ROS production and blocking of several intracellular signaling pathways. We have also previously reported that the production of ROS is a critical factor in inducing apoptosis of various cancer cells by sulforaphane, and mitotic arrest is also dependent on ROS production (Choi et al. 2008; Jo et al. 2014; Park et al. 2014).

AMP-activated protein kinase (AMPK), a serine/threonine kinase, is a metabolic-sensing protein kinase that plays an essential role in regulating cellular energy homeostasis during cell proliferation (Hardie et al. 2006; Kim and He 2013; Rehman et al. 2014). AMPK is activated in response to the phosphorylation of the critical amino acid residue Thr172 due to an increase in the ratio of intracellular AMP to ATP and phosphorylation by several upstream AMPKs (Hawley et al. 1996; Woods et al. 2003; Shaw et al. 2004). Several studies have shown that AMPK plays an important role in the induction of cell cycle arrest and the proapoptotic pathway in many cancer cell types, which is frequently accompanied by an increase in the generation of intracellular ROS (Duong et al. 2012; Sook et al. 2014; Li et al. 2016). Therefore, AMPK signaling has been considered as an attractive therapeutic target for cancer treatment in recent years. Recently, it has been shown that sulforaphane promotes lipolysis through hormone-sensitive lipase acti- vation and inhibits lipogenesis by reducing the activation of AMPK signaling (Lee et al. 2012; Choi et al. 2014). In addition, sulforaphane has been shown to protect prionmediated neurotoxicity induced by the AMPK signaling pathway in human neurons, and it has been reported that lipid toxicity and cardiomyopathy can be prevented through the attenuation of AMPK inactivation by oxidative stress (Lee et al. 2014; Zhang et al. 2014). However, the correlation between ROS generation and AMPK activation in sulforaphane-induced cell cycle arrest and apoptosis has not yet been identified. Therefore, in this study, we performed experiments to investigate the roles of ROS and AMPK in sulforaphane-induced growth inhibition using AGS human gastric adenocarcinoma cells.

\section{Materials and Methods}

\section{Cell culture and sulforaphane treatment}

AGS human gastric cancer cells were obtained from the American Type Culture Collection (Manassas, MD, USA). The cells were grown in Roswell Park Memorial Institute (RPMI) 1640 medium (WelGENE Inc, Daegu, Republic of Korea) supplemented with $10 \%$ fetal bovine serum and antibiotics (100 U/ml penicillin and $100 \mu \mathrm{g} / \mathrm{ml}$ streptomycin) and maintained as a monolayer culture at sub-confluence in a $95 \%$ air and $5 \% \mathrm{CO}_{2}$ humidified atmosphere at $37^{\circ} \mathrm{C}$. Sulforaphane (1-isothiocyanato-4-(methylsulfinyl)-butane) was purchased from Sigma-Aldrich Chemical Co. (St. Louis, MO, USA); it was dissolved in dimethyl sulfoxide (DMSO, Sigma-Aldrich Chemical Co.) and adjusted to final concentrations using complete culture medium. At the end of incubation, cells from each well were also photographed under a phase-contrast microscope (Carl Zeiss, Oberkochen, Germany).

\section{Cell viability assay}

To evaluate the cytotoxic ability of sulforaphane, the cells were seeded in 96-well microtiter plates at a density of $1 \times 10^{3}$ cells per well. After incubation for $24 \mathrm{~h}$, the cells were treated with different concentrations of sulforaphane in the presence or absence of other agents for $48 \mathrm{~h}$. At the end of the incubation period, 3-(4,5 dimethylthiazol-2-yl)-2,5-diphenyltetrazolium bromide (MTT, Sigma-Aldrich Chemical Co.) was added to each well at $0.5 \mathrm{mg} / \mathrm{ml}$, followed by incubation at $37^{\circ} \mathrm{C}$ in dark conditions. After incubation for $3 \mathrm{~h}$, the MTT solution was removed and $200 \mu \mathrm{l}$ of $5 \%$ DMSO was added to dissolve the crystals. The viable cells were detected by reading the absorbance of formazan at $540 \mathrm{~nm}$ using an enzyme-linked immunosorbent assay (ELISA) microplate reader (Dynatech Laboratories, Chantilly, VA, USA). The 
optical density of the formazan formed in control (untreated) cells was used to represent $100 \%$ viability (Hong et al. 2016).

\section{Cell cycle distribution analysis}

To analyze the cell cycle progression, the cells were removed from plates via trypsinization and pooled with cell culture supernatant containing nonadherent cells. The cells were washed twice with phosphate-buffered saline (PBS), followed by fixation with $70 \%$ ethanol, and stored at $-20^{\circ} \mathrm{C}$ overnight. After washing with PBS, the cells were stained with $50 \mu \mathrm{g} / \mathrm{ml}$ of propidium iodide (PI, Sigma-Aldrich Chemical Co.) solution containing $50 \mu \mathrm{g} /$ $\mathrm{ml}$ of RNase A and $0.1 \%$ Triton X-100 for $10 \mathrm{~min}$ in the dark at room temperature. Then, the cell cycle distribution was determined using a FACScan flow cytometer (Becton Dickinson, San Jose, CA, USA), and the percentage of cells at different cell cycle phases was analyzed using ModFitLT V3.0 software (Becton Dickinson).

\section{Detection of nuclear morphological changes}

Apoptotic cells containing chromatin condensation and nuclear fragmentation in the nuclei were detected by 4,6-diamidino-2-phenylindole (DAPI) staining. Briefly, the cells were harvested, washed with PBS twice, and fixed with $3.7 \%$ paraformaldehyde (Sigma-Aldrich Chemical Co.) in PBS for $10 \mathrm{~min}$ at $25^{\circ} \mathrm{C}$. The fixed cells were washed with PBS and stained with $1 \mathrm{mg} / \mathrm{ml}$ of DAPI solution (SigmaAldrich Chemical Co.) for $10 \mathrm{~min}$. The cells were then washed twice with PBS, and the morphology changes in the nucleus were observed using a fluorescence microscope (Carl Zeiss).

\section{Western blot analysis}

As described previously (Lee et al. 2016a), the cells were collected and lysed with cell lysis buffer; following this, protein concentrations were determined using the Bio-Rad protein assay kit (Bio-Rad, Hercules, CA, USA). In a parallel experiment, the mitochondrial and cytosolic fractions were isolated using a mitochondrial fractionation kit (Active Motif, Carlsbad, CA, USA) according to the manufacturer's instructions. For Western blotting, equal amounts of protein samples were separated by sodium dodecyl sulfate-polyacrylamide gel electrophoresis (SDS-PAGE) and transferred onto polyvinylidene difluoride membranes (Schleicher \& Schuell, Keene, NH, USA) at $350 \mathrm{~mA}$ for $1 \mathrm{~h}$ at room temperature. Subsequently, the membranes were blocked with $5 \%$ nonfat dry milk/Tris-buffered saline containing $0.1 \%$ Triton X-100 (TBST) for $1 \mathrm{~h}$; the membranes were then probed with specific primary antibodies at $4^{\circ} \mathrm{C}$ overnight. After washing the primary antibodies with TBST, the membranes were incu- bated with the appropriate horseradish peroxidase (HRP)conjugated secondary antibodies (Amersham Biosciences, Westborough, MA, USA) for $2 \mathrm{~h}$ at room temperature. The protein bands were visualized using an enhanced chemiluminescence (ECL) kit (Amersham Biosciences) according to the manufacturer's instructions.

\section{Apoptosis analysis using flow cytometry}

The apoptosis rate was determined using an annexin V-fluorescein isothiocyanate (FITC) apoptosis detection kit (BD Bioscience, San Jose, CA, USA) according to the manufacturer's instructions. Briefly, the cells were harvested, washed twice with binding buffer and stained with annexin $V$ and PI for 20 minutes in the dark. The mixture was then analyzed using a flow cytometer. The degree of apoptosis was quantified as a percentage of the annexin $\mathrm{V}$-positive and PI-negative (annexin $\mathrm{V}^{+} / \mathrm{PI}^{-}$) cells (Lee et al. 2016b).

\section{Measurement of mitochondrial membrane potential (MMP)}

Changes in the MMP after sulforaphane treatment were measured by staining with 5,5',6,6'-tetrachloro-1,1,3,3'tetraethyl-imidacarbocyanine iodide (JC-1, Sigma-Aldrich Chemical Co.), as described previously (Yao et al. 2016). Briefly, the cells were collected and incubated with $10 \mu \mathrm{M}$ JC-1 for $30 \mathrm{~min}$ in the dark at $37^{\circ} \mathrm{C}$. After removing the dye by washing with PBS, the cells were immediately analyzed using a flow cytometer.

\section{Determination of intracellular ROS}

To monitor the intracellular ROS production, we utilized cell-permeable, oxidation-sensitive fluorescent 5,6-carboxy-2'7'-dichlorofluorescein diacetate (DCF-DA) probes (Molecular Probes Inc, Leiden, Netherlands), as previously described (Kim 2016). In brief, samples of $2 \times 10^{4}$ cells were placed on six-well plates and preincubated with $10 \mu \mathrm{M}$ DCF$\mathrm{DA}$ for $30 \mathrm{~min}$ at $37^{\circ} \mathrm{C}$ in the dark. The cells were harvested and washed with PBS twice; they were then immediately analyzed using a flow cytometer. To confirm the involvement of elevated ROS in sulforaphane-induced cytotoxicity, the cells were preincubated with $\mathrm{N}$-acetylcysteine (NAC, Sigma-Aldrich Chemical Co.), an established antioxidant, for $2 \mathrm{~h}$ before treatment with sulforaphane.

\section{Statistical analysis}

All numerical data are expressed as the mean \pm standard deviation (SD). Significant differences between mean values were analyzed using the Student's $t$-test. All statistical analyses were conducted using the Statistical Package for the Social Sciences version 17.0 software (SPSS Inc, Chicago, 
IL, USA). Values of $p<0.05$ were considered to indicate statistical significance.

\section{Results}

\section{Sulforaphane inhibits cell viability in AGS cells}

Using MTT assay, the effect of sulforaphane on the growth of AGS human gastric cancer cells was evaluated. As shown in Fig. 1A, the AGS cell viability was not significantly decreased with a concentration of sulforaphane lower than $2.5 \mu \mathrm{M}$ for $48 \mathrm{~h}$. However, concentrations of sulforaphane ranging from $5 \mu \mathrm{M}$ to $20 \mu \mathrm{M}$ all exerted concentrationdependent cytotoxic effects on AGS cell growth, and treatment with $20 \mu \mathrm{M}$ sulforaphane resulted in almost $60 \%$ inhibition.

\section{Sulforaphane induces mitotic arrest in AGS cells}

In many cases, inhibition of proliferation of cancer cells by chemotherapeutic agents is associated with cell cycle arrest. Therefore, flow cytometry analysis was performed to investigate the relationship between inhibition of proliferation and cell cycle progression of AGS cells by sulforaphane. As shown in Fig. 1B, exposure to sulforaphane led to an increase in the number of G2/M phase cells as well as a simultaneous decrease in G1 phase cells in a concentration-dependent manner. For example, the populations of cells in $\mathrm{G} 2 / \mathrm{M}$ phase elevated $59.46 \%$ in
$20 \mu \mathrm{M}$ sulforaphane-treated cells compared with $17.25 \%$ in the control group. The results suggested that sulforaphane can induce G2/M arrest to decelerate cell cycle progression and prevent the cells from entering the G1 phase and proliferating. To understand the mechanism underlying sulforaphane-induced $\mathrm{G} 2 / \mathrm{M}$ arrest, we examined the effects of sulforaphane on the expression level of key regulators responsible for $\mathrm{G} 2 / \mathrm{M}$-phase checkpoints using Western blot analysis. In comparison to the control cells, there was a marked increase in the expression of cyclin B1 in AGS cells when treated with sulforaphane even though the expression of cyclin-dependent kinase 1 (Cdk1) and Cdk2 was not changed. In addition, the expression of tumor suppressor p53 and Cdk inhibitor p21 (WAF1/CIP1), a member of the Cip/Kip family proteins, was concentration-dependently increased when cells were treated with sulforaphane (Fig. 2).

Since it is difficult to distinguish between G2 and M arrest through cytometric analysis alone, we investigated whether sulforaphane induces phosphorylation of histone $\mathrm{H} 3$ protein, which is exclusively phosphorylated at serine 10 during mitosis by aurora kinase (Murnion et al. 2001). As consistent with our previous observation in human bladder cancer (Park et al. 2014), the immunoblotting results showed that sulforaphane treatment markedly enhanced the phosphorylation level of histone $\mathrm{H} 3$ compared with the untreated control group (Fig. 2); this suggesting that inhibition of AGS cell proliferation by sulforaphane treatment is closely associated with mitotic arrest in the cell cycle.

A

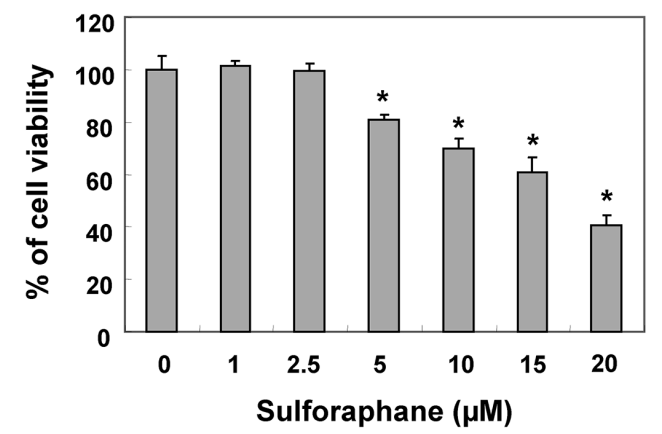

Sulforaphane $(\mu \mathrm{M})$
B

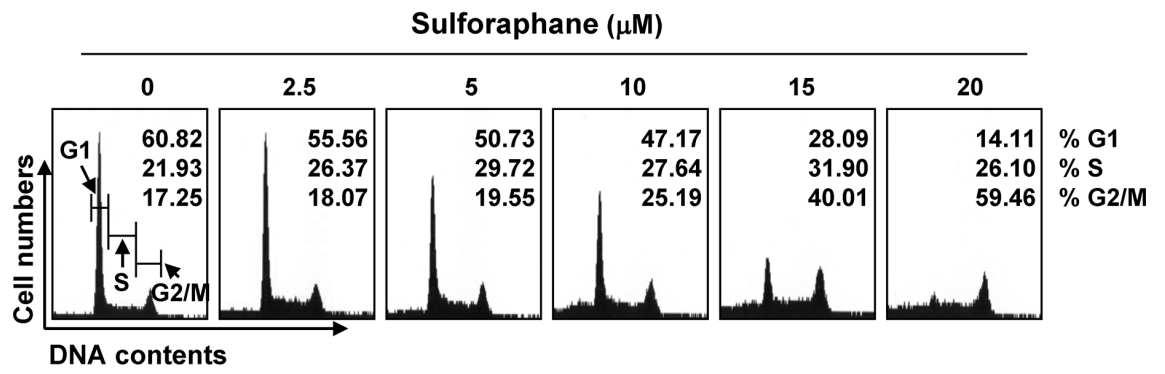

Figure 1. Effects of sulforaphane on the cell viability and cell cycle progression in AGS cells. Cells were treated with the indicated concentrations of sulforaphane for $48 \mathrm{~h}$. A. Cell viability was determined by an assay. The data are the mean \pm SD of three separate experiments. ${ }^{\star} p<0.05$ $v s$. untreated control. B. The cells were stained with PI and analyzed using flow cytometry. The results are expressed as the percentage of cell distribution at each phase; one image representing each concentration at $48 \mathrm{~h}$ is shown. 


\section{Sulforaphane enhances apoptosis in AGS cells}

We next investigated whether proliferation inhibition and mitotic arrest induced by sulforaphane were associated with apoptosis induction. The results in Fig. 3A showed that analysis by an inverted microscopy revealed distinct morphological changes in sulforaphane-treated cells. Sulforaphane-treated cells were variable in size, with extensive cytosolic vacuolization, the appearance of irregular cell membrane buds, membrane shrinkage, and cell rounding up. In addition, the morphological changes associated with apoptosis, such as chromatin condensation and nuclear fragmentation, were evident in AGS cells after sulforaphane treatment. Moreover, the cleavages of poly-ADP-ribose polymerase (PARP), a characteristic of apoptosis, were determined to further assess apoptosis. As shown in Fig. 3B, when challenged with sulforaphane, cleaved PARP increased as the concentration levels rose, as illustrated by the generation of an $85-\mathrm{kDa}$ band. To quantitatively assess the degree of apoptosis induced by sulforaphane treatment, annexin V staining was attempted; this detects phosphatidylserine in the outer membrane. The flow cytometry results indicated that AGS cells treated with sulforaphane led to a markedly increased apoptotic ratio compared with controls (Fig. 3C), and the effect was concentration-dependent. These observations suggested that the proliferation inhibition and mitotic arrest effects of sulforaphane in AGS cells are related to apoptosis induction.

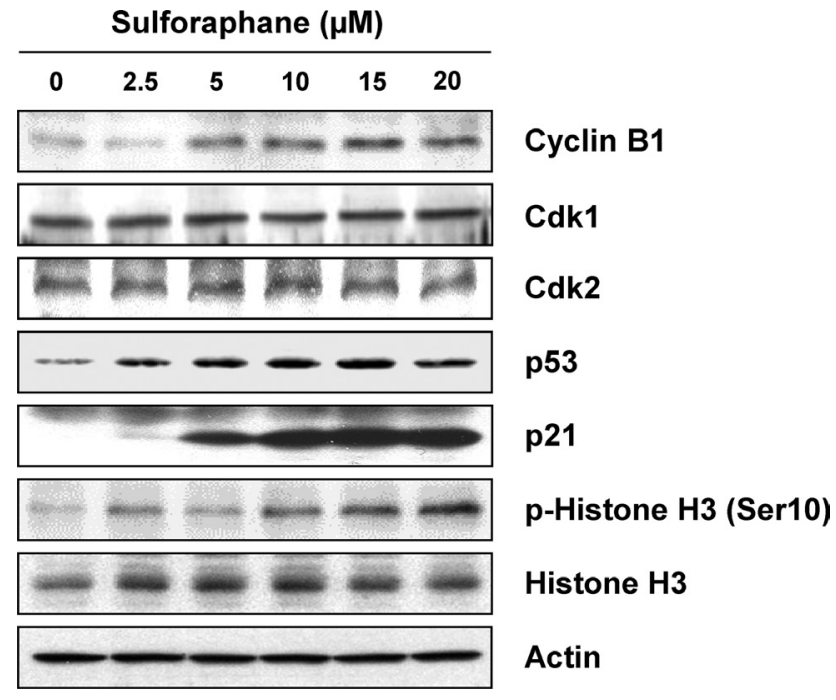

Figure 2. Effects of sulforaphane on the levels of cell cyclerelated proteins and histone H3 in AGS cells. After treatment with the indicated concentrations of sulforaphane for $48 \mathrm{~h}$, the cells were lysed and cellular proteins were separated by SDSPAGE and transferred to membranes. The membranes were probed with the indicated antibodies. Proteins were visualized using an ECL detection system. Equal loading was confirmed using actin as an internal control. The results shown are from one representative experiment of three experiments that exhibited similar patterns.
A

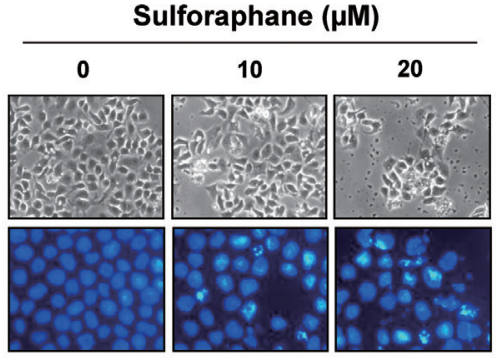

B

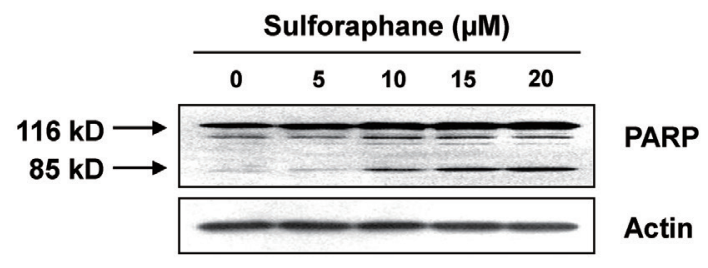

Sulforaphane $(\mu \mathrm{M})$

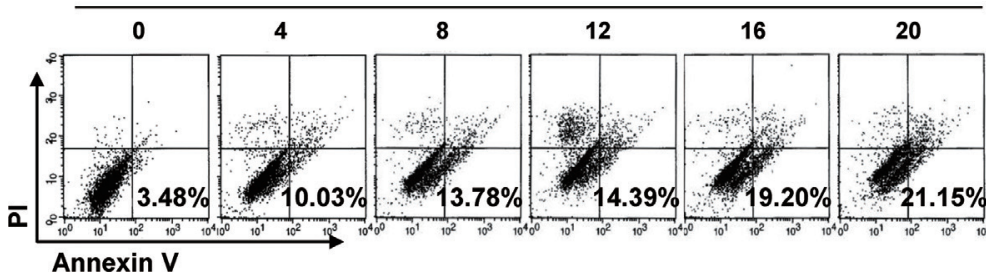

Figure 3. Induction of apoptosis by sulforaphane treatment in AGS cells. Cells were treated with the indicated concentrations of sulforaphane for $48 \mathrm{~h}$. A. The morphological changes in the cells were imaged using an inverted microscope (original magnification, $\times 200$; upper panels). The cells were fixed and stained with DAPI solution. Stained nuclei were then observed with a fluorescence microscope (original magnification, $\times 400$; lower panels). B. The cellular proteins were separated by SDS-PAGE and transferred to membranes. The membranes were probed with anti-PARP antibody. Proteins were visualized using an ECL detection system. Actin was used as an internal control. C. The cells were stained with annexin $\mathrm{V}$ and PI, and the percentages of apoptotic cells were analyzed using flow cytometric analysis. Each point represents the mean of two independent experiments. 
Activation of $A M P K$ is involved in sulforaphane-induced apoptosis in AGS cells

Because the AMPK signaling pathway plays an important role in apoptosis induction (Kim and He 2013; Rehman et al. 2014), we investigated whether this pathway is involved in apoptosis associated with sulforaphane. As shown in Fig. 4A, sulforaphane treatment led to an increase in the phosphorylated AMPK level (Thr 172) but did not cause changes in the total AMPK level. In addition, the amount of phosphorylated acetyl-CoA carboxylase (ACC, Ser 79), a major target kinase of AMPK (Hopkins et al. 2003), was augmented in a concentration-dependent manner. To examine whether sulforaphane-induced apoptosis is related to AMPK activation, we treated the cells with an AMPK inhibitor, compound C, prior to the addition of sulforaphane. The DAPI staining and flow cytometry results shown in Fig. $4 \mathrm{~B}$ and $\mathrm{C}$ demonstrated that compound $\mathrm{C}$ could abolish sulforaphane-induced apoptosis in AGS cells. Conversely, the blocking of AMPK signaling significantly inhibited sulforaphane-mediated cell viability loss (Fig. 4D). Collectively, our results suggested that activation of AMPK signaling is important for sulforaphane-induced cytotoxicity in AGS cells.

\section{ROS generation is associated with sulforaphane-induced apoptosis in AGS cells}

ROS generation is usually associated with apoptosis related to impaired mitochondrial function (Kim et al. 2016). Therefore, we used an oxidation-sensitive fluorescent dye, DCF-DA, to test the level of ROS generation in sulforaphanetreated AGS cells. As can be seen in Fig. 5A, intracellular ROS levels increased rapidly after treatment with sulforaphane and decreased again after $2 \mathrm{~h}$. MMP values were also measured using JC-1 to investigate whether the increased production of ROS by sulforaphane treatment was associated with mitochondrial function impairment. The results in Fig. 5B show that sulforaphane caused a concentration-dependent loss of MMP in comparison to the untreated control. Since the breakdown of the MMP is amongst the sequences of events occurring during the mitochondrial-mediated apoptotic pathway, this study examined the effects of sulforaphane on the levels of cytochrome $c$. As indicated in Fig. 5C, Western blot analyses revealed a progressive decrease in mitochondrial cytochrome $c$ and a concurrent increase in cytosolic cytochrome $c$ in response to sulforaphane treatment. These results further showed that sulforaphane induces the loss of MMP, thereby resulting in mitochondrial dysfunction, re-
A

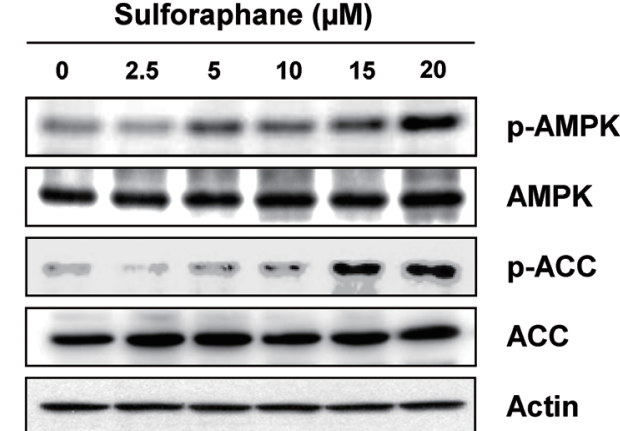

B

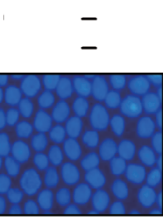
$+$
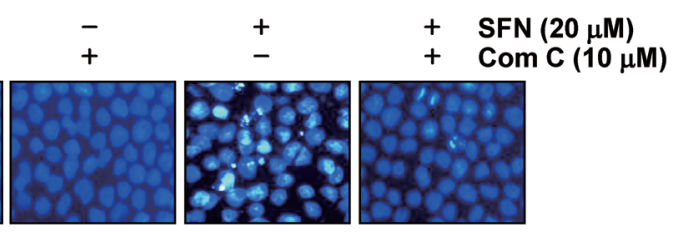

C

D
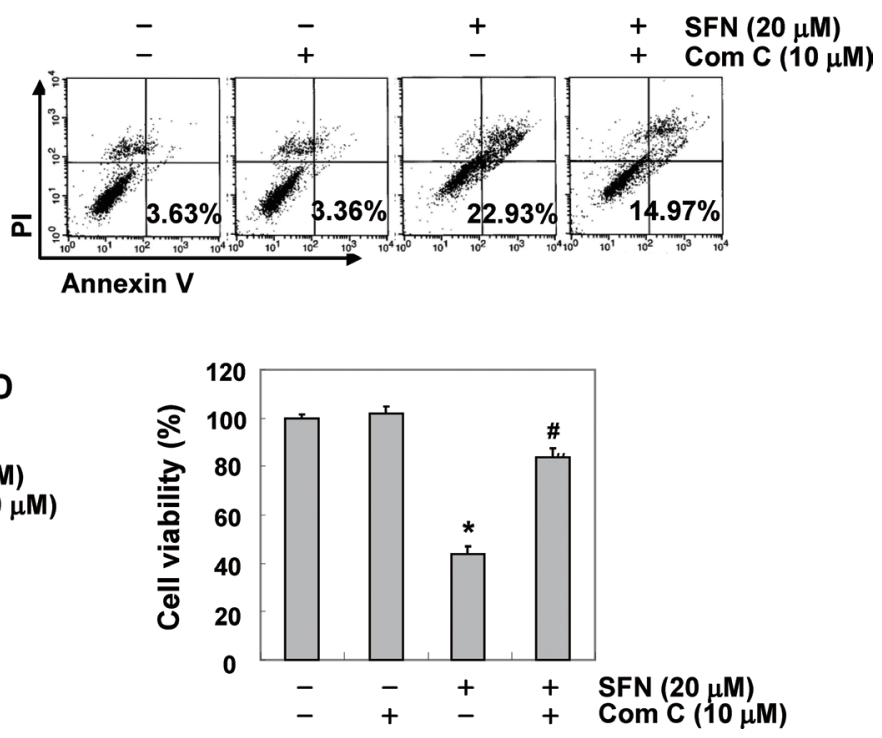

Figure 4. Activation of AMPK by sulforaphane and the effects of AMPK inhibitors on sulforaphane-induced apoptosis in AGS cells. A. Cells were treated with the indicated concentrations of sulforaphane for $48 \mathrm{~h}$. The cells were lysed and cellular proteins were separated by SDS-PAGE and transferred to membranes. The membranes were probed with the indicated antibodies. Proteins were visualized using an ECL detection system. Equal loading was confirmed using actin as an internal control. B., C. The cells were pretreated with $10 \mu \mathrm{M}$ compound C, an AMPK inhibitor, for $1 \mathrm{~h}$ and then with $20 \mu \mathrm{M}$ sulforaphane for an additional $48 \mathrm{~h}$. B. Nuclei were stained with a DAPI solution and observed with a fluorescence microscope (original magnification, $\times 400$ ). C. The percentage of apoptotic cells was analyzed using flow cytometry. Each point represents the means of two independent experiments. D. Cell viability was analyzed using an MTT assay. The data are expressed as means \pm SD of triplicate samples. The significance was determined by the Student $t$-test $\left({ }^{*} p<0.05 v\right.$ s. untreated control; ${ }^{\#} p<0.05 v s$. sulforaphane-treated cells). 
A

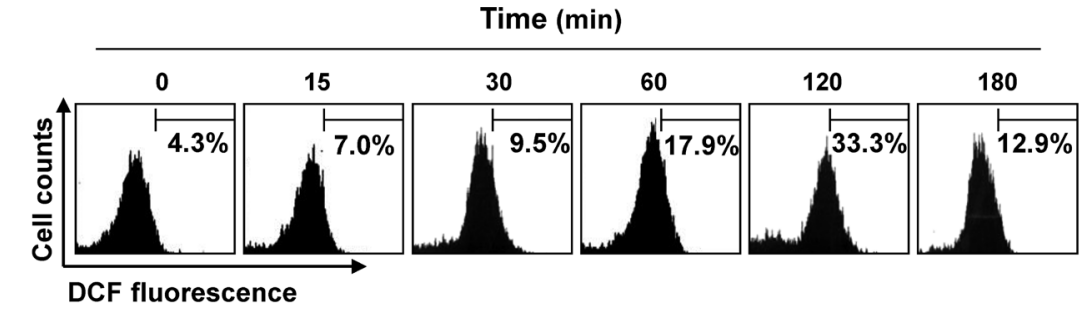

B

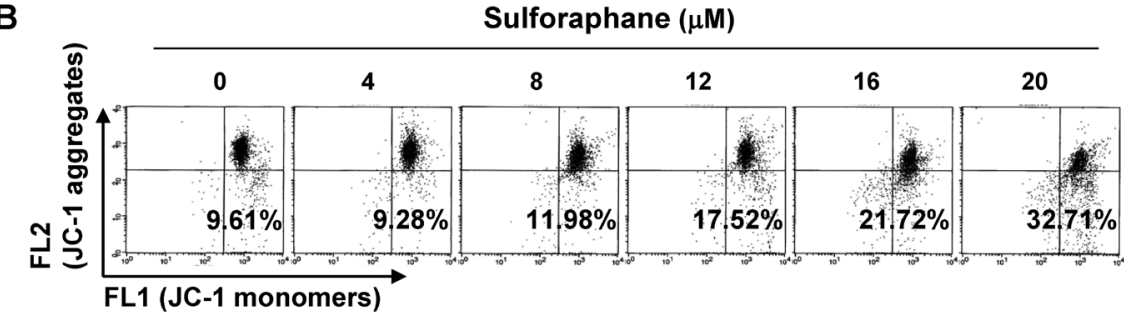

C

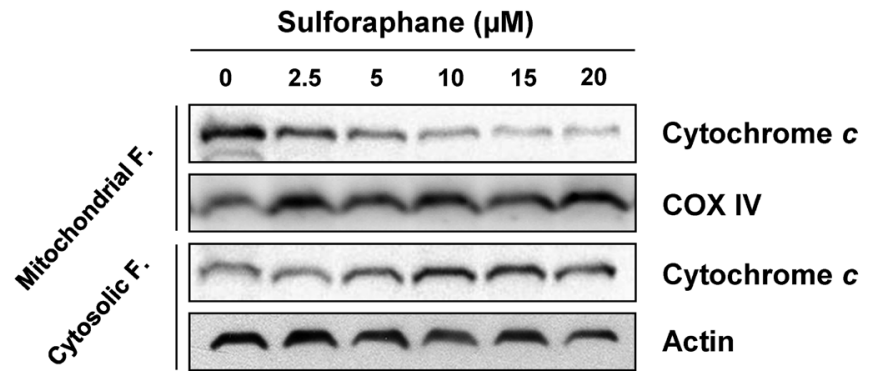

Figure 5. Increase in ROS generation, loss of MMP and translocation of cytochrome $c$ into the cytosol by treatment of AGS cells with sulforaphane. Cells were treated with $20 \mu \mathrm{M}$ sulforaphane for the indicated times (A) or the indicated concentrations of sulforaphane for $48 \mathrm{~h}$ (B and $\mathrm{C}$ ). A. The medium was discarded and cells were incubated at $37^{\circ} \mathrm{C}$ in the dark for 20 min with new culture medium containing $10 \mu \mathrm{M}$ DCFDA. ROS generation was measured using a flow cytometer. B. The cells were collected and incubated with $10 \mu \mathrm{M} \mathrm{JC}-1$ for $20 \mathrm{~min}$ at $37^{\circ} \mathrm{C}$ in the dark. The cells were then washed with PBS and the values of MMP were analyzed using a flow cytometer. C. The mitochondrial and cytosolic proteins were extracted and separated by SDS-PAGE, followed by Western blot analysis using anti-cytochrome $c$ antibody and an ECL detection system. Cytochrome oxidase IV (COX IV) and actin were used as internal controls for the mitochondrial and cytosolic fractions, respectively. lease of cytochrome $c$ from the mitochondria to the cytosol, and apoptosis induction.

To evaluate the role of ROS in sulforaphane-induced apoptosis, AGS cells were pretreated with an antioxidant NAC before sulforaphane administration. As shown in Fig. $6 \mathrm{~A}$ and $\mathrm{B}$, the sulforaphane-induced ROS generation and loss of MMP were markedly blocked by pretreatment with NAC, revealing that ROS contributed to the sulforaphane-induced dissipation in MMP. Furthermore, the degradation of PARP and translocation of cytochrome $c$ were both completely reversed when cells were pretreated with NAC before applying sulforaphane (Fig. 6D). Moreover, the flow cytometry analysis and MTT assay also demonstrated that the blocking of ROS generation with NAC significantly reduced the apoptotic ratio and cell growth inhibition, respectively (Fig. 6C and $\mathrm{E}$ ). Together, these data confirmed that ROS generation plays a critical role in the mitochondria-mediated apoptosisinducing activity of sulforaphane in AGS cells.

ROS generation are involved in sulforaphane-induced AMPK activation in AGS cells

Recent studies have shown that ROS generation is one of the most important signaling networks involved in the activation of AMPK (Kim and He 2013; Rehman et al. 2014). Therefore, we postulated that sulforaphane may induce mitotic arrest, consequently leading to apoptosis through activating ROS-mediated AMPK signaling. To study the role of ROS as upstream modulating factors for AMPK activation in sulforaphane-induced mitotic arrest of AGS cells, we investigated the phosphorylation levels of AMPK and histone $\mathrm{H} 3$ after treatment with sulforaphane in the presence or absence of NAC. As shown in Fig. 7A, NAC pretreatment perfectly protected phosphorylation of AMPK and histone $\mathrm{H} 3$ in the sulforaphane-exposed cells without a change in their total protein levels. Importantly, our results revealed that blocking the ROS generation also markedly inhibited the induction of cyclin B1 and p21 in sulforaphanestimulated AGS cells (Fig. 7A). Consistent with these studies, the flow cytometry results in Fig. 7B show that NAC pretreatment almost blocked the sulforaphane-induced increase in the number of G2/M phase cells. Therefore, our results strongly revealed that the generation of ROS plays a pivotal role in sulforaphane-triggered mitotic arrest and eventually apoptosis through the activation of AMPK signaling.

\section{Discussion}

Mounting evidence has shown that sulforaphane suppresses most cancer cell proliferation and induces apoptosis in 
A

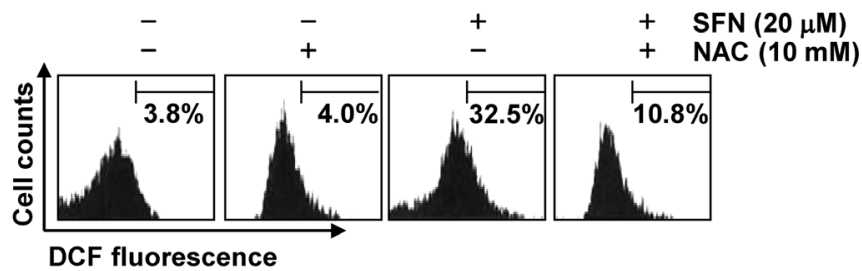

B

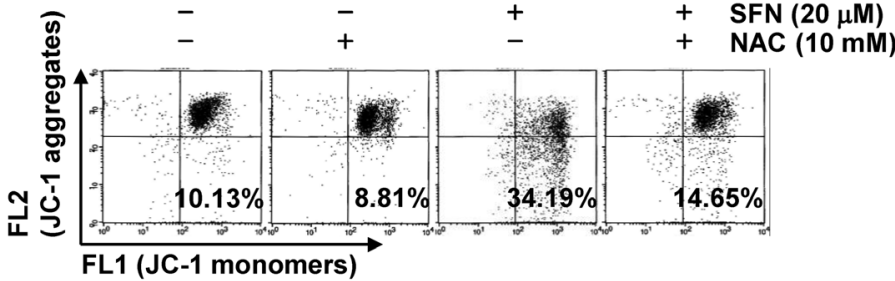

C

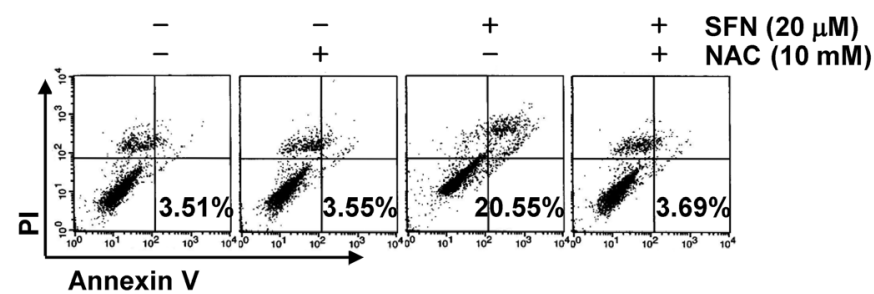

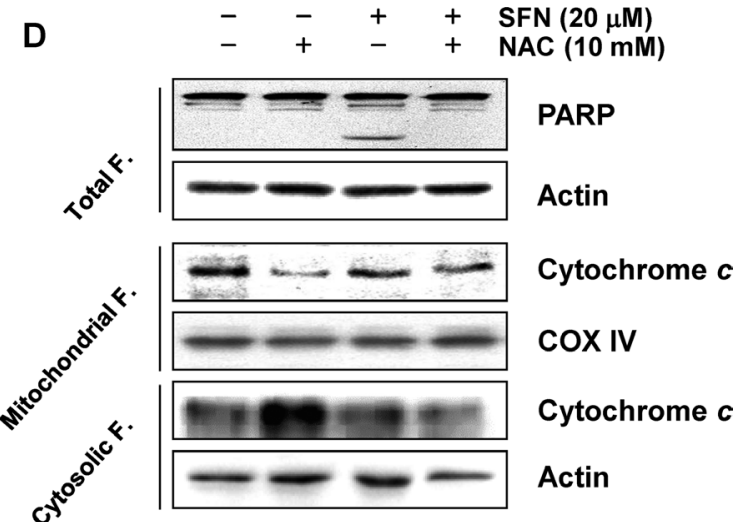

E

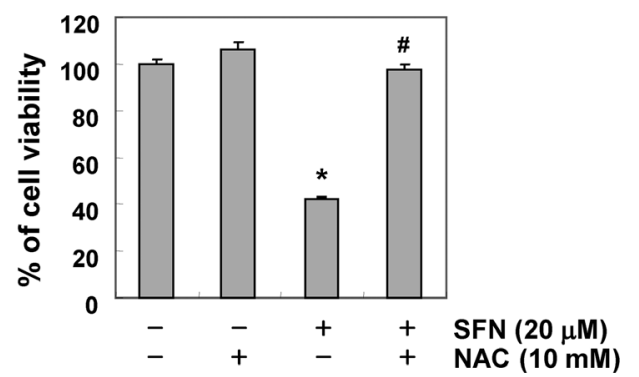

Figure 6. Induction of ROS-dependent apoptosis by sulforaphane in AGS cells. Cells were pretreated with $10 \mathrm{mM}$ NAC for $2 \mathrm{~h}$ prior to $20 \mu \mathrm{M}$ sulforaphane treatment. A. After $2 \mathrm{~h}$ of incubation, ROS generation was detected using DCF-DA. B. The loss of MMP was investigated using JC-1 following $48 \mathrm{~h}$ treatment with $20 \mu \mathrm{M}$ sulforaphane. C. After $48 \mathrm{~h}$ of incubation, the cells were stained with annexin $\mathrm{V}$, and the percentages of apoptotic cells were then analyzed using flow cytometry. The results are expressed as the mean of two independent experiments (A-C). D. The proteins were separated by SDS-PAGE and then transferred to membranes. The membranes were probed with the indicated antibodies. Proteins were visualized using an ECL detection system. E. Cell viability was analyzed using an MTT assay. The data are expressed as means \pm SD of triplicate samples. The significance was determined by Student's $t$-test $\left({ }^{*} p<\right.$ 0.05 vs. untreated control).

conditions where there is no significant effect on normal cells. The anticancer efficacy of sulforaphane was found to be associated with mitosis-specific arrest during cell cycle progression and ROS production (Kim et al. 2016; RedzaDutordoir and Averill-Bates, 2016). Recently, it has been reported that inhibition of cancer cell proliferation by natural products with anticancer activity is related to the activity of the AMPK pathway (Sook et al. 2014), and sulforaphane has been reported to activate AMPK in some experimental systems (Lee et al. 2012; Choi et al. 2014; Lee et al. 2014; Zhang et al. 2014); however, the underlying mechanism related to anticancer activity is not well known. In the current study, we investigated the relationship between ROS and the AMPK pathway in the induction of apoptosis associated with cell cycle arrest by sulforaphane in AGS gastric cancer cells. Our results revealed for the first time that sulforaphane induces mitotic arrest and apoptosis of AGS cells via a ROSdependent activation of AMPK signaling.

It has been found that excessive production of ROS that cannot be attenuated by intracellular redox systems in many cancer cell lines can not only arrest cell cycle but also induce apoptosis (Kim et al. 2016; Redza-Dutordoir and AverillBates 2016). This means that generation of ROS can act as a secondary messenger device to regulate the intracellular signaling pathways for antitumoral function, suggesting that excessive ROS production is an important factor in determining the fate of cancer cells. Our flow cytometry study showed that sulforaphane-induced inhibition of AGS cell proliferation was associated with G2/M arrest, which is consistent with some previous results (Singh et al. 2004; Matsui et al. 2007; Chu et al. 2009; Suppipat et al. 2012; Wang et al. 2015; Byun et al. 2016; Shang et al. 2017). In this process, expression of p21 was increased with the increase of p53 expression, which was also in good agreement with previous results observed in some cancer cells (Herman-Antosiewicz et al. 2007). Interestingly, the expression of cyclin B1 was increased in the absence of changes in the expression of Cdks, such as Cdk1 and Cdk2, and the enhanced phosphorylation of histone $\mathrm{H} 3$ was observed with sulforaphane treatment. Although, it has been reported that cyclin B1 expression is 
inhibited in cervical cancer cells during mitosis arrest by sulforaphane treatment (Cheng et al. 2016), its expression is increased in the mitotic arrest process by sulforaphane treatment in many cancer cells, including bladder, prostate, and breast cancer cell lines (Jackson and Singletary 2004; Herman-Antosiewicz et al. 2007; Park et al. 2014), as shown in this study. Thus, it can be inferred that cell cycle arrest by sulforaphane occurs specifically at the mitosis stage, considering that histone $\mathrm{H} 3$ phosphorylation, accompanied by increased cyclin B1 expression, is a hallmark of mitotic stasis (Murnion et al. 2001).

We also investigated whether cell cycle arrest of AGS cells by sulforaphane is associated with apoptosis induction of by morphological nuclear changes, degradation of PARP protein, and flow cytometry through annexin $\mathrm{V}$ staining. The apoptosis-induction pathway known to date is divided into an extrinsic pathway involving the death receptor and an intrinsic pathway emerging as the center of the mitochondria. Both pathways depend on caspase activation, and the intrinsic apoptosis pathway is accompanied by the loss of MMP and cytochrome $c$ release in the cytoplasm (Koff et al. 2015; Westhoff et al. 2016). In the present study, sulforaphane-triggered apoptosis was accompanied by increased MMP loss, generation of ROS, and translocation of cytochrome $c$ from the mitochondria to the cytoplasm, which was similar to previous study by Mondal et al. (2016).

Although some prior studies have reported that the extrinsic and intrinsic pathways are simultaneously activated in apoptosis induction by sulforaphane, our results give good support for several previous studies suggesting that sulforaphane-induced apoptosis is caspase mediated in relation to mitochondrial dysfunction (Singh et al. 2005; Rudolf et al. 2009; Xiao et al. 2009; Negrette-Guzmán et al. 2013; Mondal et al. 2016). In particular, the increased expression of pro-apoptotic Bax protein by sulforaphane is associated with increased ROS production and activation of intrinsic apoptosis pathway associated with cytosolic release of cytochrome $c$ and loss of MMP (Jo et al. 2014; Mondal et al. 2016; Shang et al. 2017). However, when the production of ROS was artificially blocked, induction of apoptosis by sulforaphane was completely blocked, indicating that induction of apoptosis by sulforaphane in AGS cells is due to ROS production dependent mitochondrial dysfunction.

According to the results of many recent results, the activation of AMPK signaling pathway is a key factor in inducing apoptosis of cancer cells, which is reported to be associated with energy metabolism disturbance (Hopkins et al. 2003; Hardie et al. 2006). Since mitochondria are the key organ of energy production in cells and mitochondrial dysfunction in mitochondria-mediated apoptosis processes disturbs intracellular energy metabolism, AMPK is recognized as a new target to control cancer cell proliferation (Kim and He 2013; Rehman et al. 2014). Nevertheless, the
A
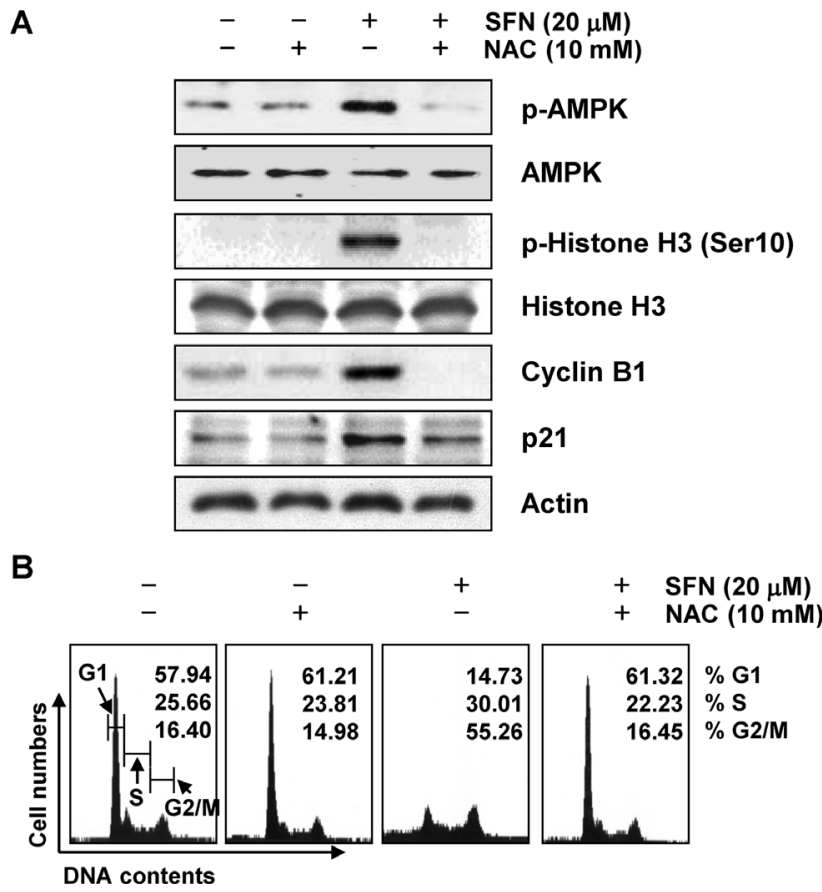

Figure 7. Effects of ROS inhibition on the sulforaphane-induced phosphorylation of AMPK and histone $\mathrm{H} 3$ and expression of cyclin B1 and p21 in AGS cells. A. Cells were pretreated with $10 \mathrm{mM} \mathrm{NAC}$ for $2 \mathrm{~h}$ and then with $20 \mu \mathrm{M}$ sulforaphane for an additional $48 \mathrm{~h}$. Total cellular proteins were subjected to SDS-polyacrylamide gels and Western blotting for the detection of the indicated proteins. Actin was used as an internal control. B. Cells grown under the same conditions as (A) were collected and analyzed by flow cytometry. The results are expressed as the percentage of cell distribution at each phase. The data are expressed as the means of two samples.

role of AMPK in the inhibition of cancer cell proliferation by sulforaphane has not been studied to date. According to the results of our current study, the phosphorylation of ACC, its downstream target of AMPK, and AMPK, was apparently dependent on the treatment concentration of sulforaphane, indicating that the AMPK pathway was activated in sulforaphane-stimulated AGS cells. However, when compound C, an inhibitor of AMPK, was treated with sulforaphane at the same time, apoptosis induction by sulforaphane was significantly blocked, and the decreased cell viability returned to almost normal level; this indicated that activation of AMPK was required for sulforaphane-induced cytotoxicity in AGS cells. Interestingly, when ROS production was blocked, activation of AMPK, which was increased in sulforaphane-treated AGS cells, was also completely blocked. In addition, expressions of cyclin B1 and p21 were inhibited simultaneously, as well as the phosphorylation of histone $\mathrm{H} 3$, representing mitotic arrest. Moreover, the increased frequency of the cells belonging to the G2/M phase by sulforaphane treatment was restored to normal 
level. These results strongly suggest that mitotic arrest and induction of apoptosis by sulforaphane are mediated by ROS-dependent AMPK pathway activation.

In conclusion, the results of this study revealed that inhibition of AGS cell proliferation by sulforaphane is mediated by apoptosis induction associated with mitotic arrest, and that ROS production and increased AMPK activation are involved in this process. It was also found that the generation of ROS acts as a potential upstream factor for sulforaphaneinduced AMPK activation. Although further studies on the role of AMPK in energy homeostasis following mitochondrial disturbance are needed, the results of this study are the first reports to show that ROS-dependent AMPK activity is involved in the inhibition of human tumor cell proliferation by sulforaphane.

Conflict of interest. The author has no conflict of interest to declare.

\section{References}

Bryant CS, Kumar S, Chamala S, Shah J, Pal J, Haider M, Seward S, Qazi AM, Morris R, Semaan A, et al. (2010): Sulforaphane induces cell cycle arrest by protecting RB-E2F-1 complex in epithelial ovarian cancer cells. Mol. Cancer 9, 47 https://doi.org/10.1186/1476-4598-9-47

Byun S, Shin SH, Park J, Lim S, Lee E, Lee C, Sung D, Farrand L, Lee SR, Kim KH, et al. (2016): Sulforaphene suppresses growth of colon cancer-derived tumors via induction of glutathione depletion and microtubule depolymerization. Mol. Nutr. Food Res. 60, 1068-1078 https://doi.org/10.1002/mnfr.201501011

Cheng YM, Tsai CC, Hsu YC (2016): Sulforaphane, a dietary isothiocyanate, induces $\mathrm{G} 2 / \mathrm{M}$ arrest in cervical cancer cells through cyclin B1 downregulation and GADD45/CDC2 association. Int. J. Mol. Sci. 17, E1530 https://doi.org/10.3390/ijms17091530

Choi WY, Choi BT, Lee WH, Choi YH (2008): Sulforaphane generates reactive oxygen species leading to mitochondrial perturbation for apoptosis in human leukemia U937 cells. Biomed. Pharmacother. 62, 637-644 https://doi.org/10.1016/j.biopha.2008.01.001

Choi KM, Lee YS, Kim W, Kim SJ, Shin KO, Yu JY, Lee MK, Lee YM, Hong JT, Yun YP, Yoo HS (2014): Sulforaphane attenuates obesity by inhibiting adipogenesis and activating the AMPK pathway in obese mice. J. Nutr. Biochem. 25, 201-207 https://doi.org/10.1016/j.jnutbio.2013.10.007

Chu WF, Wu DM, Liu W, Wu LJ, Li DZ, Xu DY, Wang XF (2009): Sulforaphane induces G2-M arrest and apoptosis in high metastasis cell line of salivary gland adenoid cystic carcinoma. Oral. Oncol. 45, 998-1004 https://doi.org/10.1016/j.oraloncology.2009.05.641

Diaz-Moralli S, Tarrado-Castellarnau M, Miranda A, Cascante M (2013): Targeting cell cycle regulation in cancer therapy. Pharmacol. Ther. 138, 255-271 https://doi.org/10.1016/j.pharmthera.2013.01.011
Duong HQ, Hwang JS, Kim HJ, Seong YS, Bae I (2012): BML-275, an AMPK inhibitor, induces DNA damage, G2/M arrest and apoptosis in human pancreatic cancer cells. Int. J. Oncol. 41, $2227-2236$

https://doi.org/10.3892/ijo.2012.1672

Fimognari C, Lenzi M, Hrelia P (2008): Interaction of the isothiocyanate sulforaphane with drug disposition and metabolism: pharmacological and toxicological implications. Curr. Drug Metab. 9, 668-678 https://doi.org/10.2174/138920008785821675

Gupta P, Kim B, Kim SH, Srivastava SK (2014): Molecular targets of isothiocyanates in cancer: recent advances. Mol. Nutr. Food Res. 58, 1685-1707 https://doi.org/10.1002/mnfr.201300684

Hardie DG, Hawley SA, Scott JW (2006): AMP-activated protein kinase-development of the energy sensor concept. J. Physiol. $\mathbf{5 7 4}, 7-15$ https://doi.org/10.1113/jphysiol.2006.108944

Hawley SA, Davison M, Woods A, Davies SP, Beri RK, Carling D, Hardie DG (1996): Characterization of the AMP-activated protein kinase kinase from rat liver and identification of threonine 172 as the major site at which it phosphorylates AMP-activated protein kinase. J. Biol. Chem. 271, 27879-27887 https://doi.org/10.1074/jbc.271.44.27879

Herman-Antosiewicz A, Xiao H, Lew KL, Singh SV (2007): Induction of $\mathrm{p} 21$ protein protects against sulforaphane-induced mitotic arrest in LNCaP human prostate cancer cell line. Mol. Cancer Ther. 6, 1673-1681 https://doi.org/10.1158/1535-7163.MCT-06-0807

Hong SH, Sim MJ, Kim YC (2016): Melanogenesis-promoting effects of Rhynchosia nulubilis and Rhynchosia volubilis ethanol extracts in melan-a cells. Toxicol. Res. 32, 141-147 https://doi.org/10.5487/TR.2016.32.2.141

Hopkins TA, Dyck JR, Lopaschuk GD (2003): AMP-activated protein kinase regulation of fatty acid oxidation in the ischaemic heart. Biochem. Soc. Trans. 31, 207-212 https://doi.org/10.1042/bst0310207

Jackson SJ, Singletary KW (2004): Sulforaphane: a naturally occurring mammary carcinoma mitotic inhibitor, which disrupts tubulin polymerization. Carcinogenesis 25, 219-227 https://doi.org/10.1093/carcin/bgg192

Jo GH, Kim GY, Kim WJ, Park KY, Choi YH (2014): Sulforaphane induces apoptosis in T24 human urinary bladder cancer cells through a reactive oxygen species-mediated mitochondrial pathway: the involvement of endoplasmic reticulum stress and the Nrf2 signaling pathway. Int. J. Oncol. 45, 1497-1506 https://doi.org/10.3892/ijo.2014.2536

Kim HK (2016): Adenophora remotiflora protects human skin keratinocytes against UVB-induced photo-damage by regulating antioxidative activity and MMP-1 expression. Nutr. Res. Pract. 10, 371-376 https://doi.org/10.4162/nrp.2016.10.4.371

Kim I, He YY (2013): Targeting the AMP-activated protein kinase for cancer prevention and therapy. Front. Oncol. 3, 175 https://doi.org/10.3389/fonc.2013.00175

Kim J, Kim J, Bae JS (2016): ROS homeostasis and metabolism: a critical liaison for cancer therapy. Exp. Mol. Med. 48, e269 https://doi.org/10.1038/emm.2016.119 
Koff J. L, Ramachandiran S, Bernal-Mizrachi L (2015): A time to kill: targeting apoptosis in cancer. Int. J. Mol. Sci. 16, 2942-2955 https://doi.org/10.3390/ijms16022942

Lee JH, Moon MH, Jeong JK, Park YG, Lee YJ, Seol JW, Park SY (2012): Sulforaphane induced adipolysis via hormone sensitive lipase activation, regulated by AMPK signaling pathway. Biochem. Biophys. Res. Commun. 426, 492-497 https://doi.org/10.1016/j.bbrc.2012.08.107

Lee JH, Jeong JK, Park SY (2014): Sulforaphane-induced autophagy flux prevents prion protein-mediated neurotoxicity through AMPK pathway. Neuroscience 278, 31-39 https://doi.org/10.1016/j.neuroscience.2014.07.072

Lee IC, Lee SM, Ko JW, Park SH, Shin IS, Moon C, Kim SH, Kim JC (2016a): Role of mitogen-activated protein kinases and nuclear factor-kappa B in 1,3-dichloro-2-propanol-induced hepatic injury. Lab. Anim. Res. 32, 24-33 https://doi.org/10.5625/lar.2016.32.1.24

Lee PY, Park BC, Chi SW, Bae KH, Kim S, Cho S, Kang S, Kim JH, Park SG (2016b): Histone H4 is cleaved by granzyme A during staurosporine-induced cell death in B-lymphoid Raji cells. BMB Rep. 49, 560-565 https://doi.org/10.5483/BMBRep.2016.49.10.105

Li Z, Wang JW, Wang WZ, Zhi XF, Zhang Q, Li BW, Wang LJ, Xie KL, Tao JQ, Tang J, Wei S, Zhu Y, Xu H, Zhang DC, Yang L, Xu ZK (2016): Natriuretic peptide receptor A inhibition suppresses gastric cancer development through reactive oxygen species-mediated G2/M cell cycle arrest and cell death. Free Radic. Biol. Med. 99, 593-607 https://doi.org/10.1016/j.freeradbiomed.2016.08.019

Liu B, Mao Q, Lin Y, Zhou F, Xie L (2013): The association of cruciferous vegetables intake and risk of bladder cancer: a meta-analysis. World J. Urol. 31,127-133 https://doi.org/10.1007/s00345-012-0850-0

Matsui TA, Murata H, Sakabe T, Sowa Y, Horie N, Nakanishi R, Sakai T, Kubo T (2007): Sulforaphane induces cell cycle arrest and apoptosis in murine osteosarcoma cells in vitro and inhibits tumor growth in vivo. Oncol. Rep. 18, 1263-1268 https://doi.org/10.3892/or.18.5.1263

Mi L, Xiao Z, Hood BL, Dakshanamurthy S, Wang X, Govind S, Conrads TP, Veenstra TD, Chung FL (2008): Covalent binding to tubulin by isothiocyanates. A mechanism of cell growth arrest and apoptosis. J. Biol. Chem. 283, 22136-22146 https://doi.org/10.1074/jbc.M802330200

Mondal A, Biswas R, Rhee YH, Kim J, Ahn JC (2016): Sulforaphene promotes $\mathrm{Bax} / \mathrm{Bcl} 2$, MAPK-dependent human gastric cancer AGS cells apoptosis and inhibits migration via EGFR, p-ERK1/2 down-regulation. Gen. Physiol. Biophys. 35, 25-34

Murnion ME, Adams RR, Callister DM, Allis CD, Earnshaw WC, Swedlow JR (2001): Chromatin-associated protein phosphatase 1 regulates aurora-B and histone $\mathrm{H} 3$ phosphorylation. J. Biol. Chem. 276, 26656-26665 https://doi.org/10.1074/jbc.M102288200

Myzak MC, Dashwood RH (2006): Chemoprotection by sulforaphane: keep one eye beyond Keap1. Cancer Lett. 233, 208-218 https://doi.org/10.1016/j.canlet.2005.02.033

Negrette-Guzmán M, Huerta-Yepez S, Tapia E, Pedraza-Chaverri J (2013): Modulation of mitochondrial functions by the indi- rect antioxidant sulforaphane: a seemingly contradictory dual role and an integrative hypothesis. Free Radic. Biol. Med. 65, 1078-1089

https://doi.org/10.1016/j.freeradbiomed.2013.08.182

Park HS, Han MH, Kim GY, Moon SK, Kim WJ, Hwang HJ, Park KY, Choi YH (2014): Sulforaphane induces reactive oxygen speciesmediated mitotic arrest and subsequent apoptosis in human bladder cancer 5637 cells. Food Chem. Toxicol. 64, 157-165 https://doi.org/10.1016/j.fct.2013.11.034

Redza-Dutordoir M, Averill-Bates DA (2016): Activation of apoptosis signalling pathways by reactive oxygen species. Biochim. Biophys. Acta 1863, 2977-2992 https://doi.org/10.1016/j.bbamcr.2016.09.012

Rehman G, Shehzad A, Khan AL, Hamayun M (2014): Role of AMP-activated protein kinase in cancer therapy. Arch. Pharm. (Weinheim) 347, 457-468 https://doi.org/10.1002/ardp.201300402

Rudolf E, Andelová H, Cervinka M (2009): Activation of several concurrent proapoptic pathways by sulforaphane in human colon cancer cells SW620. Food Chem. Toxicol. 47, 2366-2373 https://doi.org/10.1016/j.fct.2009.06.034

Sestili P, Fimognari C (2015): Cytotoxic and antitumor activity of sulforaphane: The role of reactive oxygen species. Biomed. Res. Int. 2015, 402386 https://doi.org/10.1155/2015/402386

Shang HS, Shih YL, Lee CH, Hsueh SC, Liu JY, Liao NC, Chen YL, Huang YP, Lu HF, Chung JG (2017): Sulforaphane-induced apoptosis in human leukemia HL-60 cells through extrinsic and intrinsic signal pathways and altering associated genes expression assayed by cDNA microarray. Environ. Toxicol. $32,311-328$ https://doi.org/10.1002/tox.22237

Shaw RJ, Kosmatka M, Bardeesy N, Hurley RL, Witters LA, DePinho RA, Cantley LC (2004): The tumor suppressor LKB1 kinase directly activates AMP-activated kinase and regulates apoptosis in response to energy stress. Proc. Natl. Acad. Sci. USA 101, 3329-3335

https://doi.org/10.1073/pnas.0308061100

Shen G, Xu C, Chen C, Hebbar V, Kong AN (2006): p53-independent G1 cell cycle arrest of human colon carcinoma cells HT-29 by sulforaphane is associated with induction of p21CIP1 and inhibition of expression of cyclin D1. Cancer Chemother. Pharmacol. 57, 317-327 https://doi.org/10.1007/s00280-005-0050-3

Singh SV, Herman-Antosiewicz A, Singh AV, Lew KL, Srivastava SK, Kamath R, Brown KD, Zhang L, Baskaran R (2004): Sulforaphane-induced G2/M phase cell cycle arrest involves checkpoint kinase 2-mediated phosphorylation of cell division cycle 25C. J. Biol. Chem. 279, 25813-25822

https://doi.org/10.1074/jbc.M313538200

Singh SV, Srivastava SK, Choi S, Lew KL, Antosiewicz J, Xiao D, Zeng Y, Watkins SC, Johnson CS, Trump DL, et al. (2005): Sulforaphane-induced cell death in human prostate cancer cells is initiated by reactive oxygen species. J. Biol. Chem. 280, 19911-19924

https://doi.org/10.1074/jbc.M412443200

Sook SH, Lee HJ, Kim JH, Sohn EJ, Jung JH, Kim B, Kim JH, Jeong SJ, Kim SH (2014): Reactive oxygen species-mediated activa- 
tion of AMP-activated protein kinase and c-Jun N-terminal kinase plays a critical role in beta-sitosterol-induced apoptosis in multiple myeloma U266 cells. Phytother. Res. 28, 387-394 https://doi.org/10.1002/ptr.4999

Suppipat K, Park CS, Shen Y, Zhu X, Lacorazza HD (2012): Sulforaphane induces cell cycle arrest and apoptosis in acute lymphoblastic leukemia cells. PLoS One 7, e51251 https://doi.org/10.1371/journal.pone.0051251

Tang L, Zirpoli GR, Guru K, Moysich KB, Zhang Y, Ambrosone CB, McCann SE (2010): Intake of cruciferous vegetables modifies bladder cancer survival. Cancer Epidemiol. Biomarkers Prev. 19, $1806-18011$ https://doi.org/10.1158/1055-9965.EPI-10-0008

Visconti R, Della Monica R, Grieco D (2016): Cell cycle checkpoint in cancer: a therapeutically targetable double-edged sword. J. Exp. Clin. Cancer Res. 35, 153 https://doi.org/10.1186/s13046-016-0433-9

Wang M, Chen S, Wang S, Sun D, Chen J, Li Y, Han W, Yang X, Gao HQ (2012): Effects of phytochemicals sulforaphane on uridine diphosphate-glucuronosyltransferase expression as well as cell-cycle arrest and apoptosis in human colon cancer Caco-2 cells. Chin. J. Physiol. 55, 134-144

Wang L, Tian Z, Yang Q, Li H, Guan H, Shi B, Hou P, Ji M (2015): Sulforaphane inhibits thyroid cancer cell growth and invasiveness through the reactive oxygen species-dependent pathway. Oncotarget 6, 25917-25931 https://doi.org/10.18632/oncotarget.4542

Westhoff MA, Marschall N, Debatin KM (2016): Novel approaches to apoptosis-inducing therapies. Adv. Exp. Med. Biol. 930, 173-204 https://doi.org/10.1007/978-3-319-39406-0_8

Woods A, Vertommen D, Neumann D, Turk R, Bayliss J, Schlattner U, Wallimann T, Carling D, Rider MH (2003): Identification of phosphorylation sites in AMP-activated protein kinase (AMPK) for upstream AMPK kinases and study of their roles by site-directed mutagenesis. J. Biol. Chem. 278, 28434-28442 https://doi.org/10.1074/jbc.M303946200

Xiao D, Powolny AA, Antosiewicz J, Hahm ER, Bommareddy A, Zeng Y, Desai D, Amin S, Herman-Antosiewicz A, Singh SV (2009): Cellular responses to cancer chemopreventive agent D,Lsulforaphane in human prostate cancer cells are initiated by mitochondrial reactive oxygen species. Pharm. Res. 26, 1729-1738 https://doi.org/10.1007/s11095-009-9883-5

Xiao Z, Mi L, Chung FL, Veenstra TD (2012): Proteomic analysis of covalent modifications of tubulins by isothiocyanates. J. Nutr. 142, 1377S-1381S https://doi.org/10.3945/jn.111.152041

Yao J, Jiao R, Liu C, Zhang Y, Yu W, Lu Y, Tan R (2016): Assessment of the cytotoxic and apoptotic effects of chaetominine in a human leukemia cell line. Biomol. Ther. (Seoul) 24, 147-155 https://doi.org/10.4062/biomolther.2015.093

Zhang Z, Wang S, Zhou S, Yan X, Wang Y, Chen J, Mellen N, Kong M, Gu J, Tan Y, Zheng Y, Cai L (2014): Sulforaphane prevents the development of cardiomyopathy in type 2 diabetic mice probably by reversing oxidative stress-induced inhibition of LKB1/AMPK pathway. J. Mol. Cell. Cardiol. 77, 42-52 https://doi.org/10.1016/j.yjmcc.2014.09.022

Received: April 12, 2017

Final version accepted: June 26, 2017 